\title{
Allopurinol in the treatment of acquired reactive perforating collagenosis"
}

\author{
Alopurinol no tratamento de colagenose reativa perfurante adquirida
}

\author{
Hemma Tilz ${ }^{1}$ \\ Franz Legat ${ }^{3}$ \\ Martin Inzinger ${ }^{1}$
}

\author{
Jürgen Christian Becker ${ }^{2}$ \\ Antonio Pedro Mendes Schettini ${ }^{4}$ \\ Cesare Massone ${ }^{5}$
}

\begin{abstract}
Acquired reactive perforating collagenosis is a perforating dermatosis usually associated with different systemic diseases, mainly diabetes mellitus and/or chronic renal insufficiency. Different therapies have been tried but treatment is not standardized yet and remains a challenge. In the last few years, allopurinol has been reported as a good therapeutic option for acquired reactive perforating collagenosis. We describe the case of a 73 -year-old man affected by acquired reactive perforating collagenosis associated with diabetes type 1 and chronic renal failure with secondary hyperparathyroidism. The patient was successfully treated with allopurinol 100mg once/day p.o..

Keywords: Allopurinol; Diabetes mellitus; Prurigo; Renal insufficiency, Chronic; Kidney failure, chronic

Resumo: A colagenose reativa perfurante adquirida pertence ao grupo das dermatoses perfurantes e frequentemente está associada com diferentes doenças sistêmicas, principalmente diabetes mellitus e/ou insuficiência renal crônica. Diferentes terapêuticas têm sido utilizadas, mas o tratamento ainda é um desafio, pois não existe tratamento padronizado. Nos últimos anos, alopurinol tem sido relatado como uma boa opção terapêutica para colagenose reativa perfurante adquirida. Relatamos o caso de um paciente masculino, com 73 anos de idade, portador de colagenose reativa perfurante adquirida em associação com diabetes tipo 1 e falência renal crônica com hiperparatireoidismo secundário. $\mathrm{O}$ paciente foi eficazmente tratado com alopurinol na dose $100 \mathrm{mg} / \mathrm{dia}$, via oral.

Palavras-chave: Alopurinol; Diabetes mellitus; Falência renal crônica; Insuficiência renal crônica; Prurigo
\end{abstract}

\section{INTRODUCTION}

Reactive perforating collagenosis (RPC) was described by Mehregan et al. in 1967 and belongs to the spectrum of perforating dermatoses; an inherited form and an acquired variant are known. ${ }^{1}$ The former appears early in childhood and recurs once or twice per year. On the contrary, acquired RPC (ARPC) appears late in life and is associated with different systemic diseases. Diagnostic criteria of ARPC (Faver`s criteria) are: onset of lesions after the age of 18 years; umbilicated papules or nodules with a central adherent keratotic plug; on histopathology, elimination of altered collagen through an epithelium-lined crater

Received on 01.1.2011.

Approved by the Advisory Board and accepted for publication on 08.04.2012.

* Study carried out at the Medical University of Graz - Graz, Austria.

\footnotetext{
Conflict of interest: J.C.Becker: adboard and speakers bureau for Roche and Glaxo Smith Kline Financial funding: None

MD, resident in dermatology - Department of Dermatology, Division of General Dermatology, Medical University of Graz - Graz, Austria

Professor - Director of Department of Dermatology, Division of General Dermatology, Medical University of Graz - Graz, Austria.

Professor - Professor of Department of Dermatology, Division of General Dermatology, Medical University of Graz - Graz, Austria

Master's degree in Tropical Pathology from the Federal University of Amazonas (Universidade Federal do Amazonas - UFAM); Dermatologist of the Alfredo da

Matta Foundation (Fundação "Alfredo da Matta") - Manaus (AM), Brazil.

Professor - Professor of Department of Dermatology, Division of General Dermatology, Medical University of Graz - Graz, Austria.
} 
filled with keratin. ${ }^{1}$ Skin lesions may be disseminated all over the body and itching very severe; treatment is not standardized yet and remains a challenge. ${ }^{1}$

In the last few years, allopurinol has been reported as a good therapeutic option for ARPC. ${ }^{1-6}$ We describe the case of a male patient successfully treated with allopurinol.

\section{CASE REPORT}

A 73-year-old man was admitted with intensively pruritic multiple erythematous excoriated papules and nodules with a central adherent keratotic plug up to $20 \mathrm{~mm}$ in diameter involving the whole integument. Pruritus had started 10 months before and subsequently there was onset of keratotic papules and nodules (Figure 1). The patient had suffered from diabetes type 1 for 50 years, complicated with retinopathy, cardiopathy, chronic renal failure and, in the last 5 years, also with secondary hyperparathyroidism. Medication consisted of insulin, bisoprolol, clopidogrel, telmisartan, nicorandil, furosemide, calcium dobesilate and ranitidine. Laboratory tests showed elevated creatinine $1.72 \mathrm{mg} / \mathrm{dl}(0.7-1.20)$, urea $106 \mathrm{mg} / \mathrm{dl}(10-45)$,
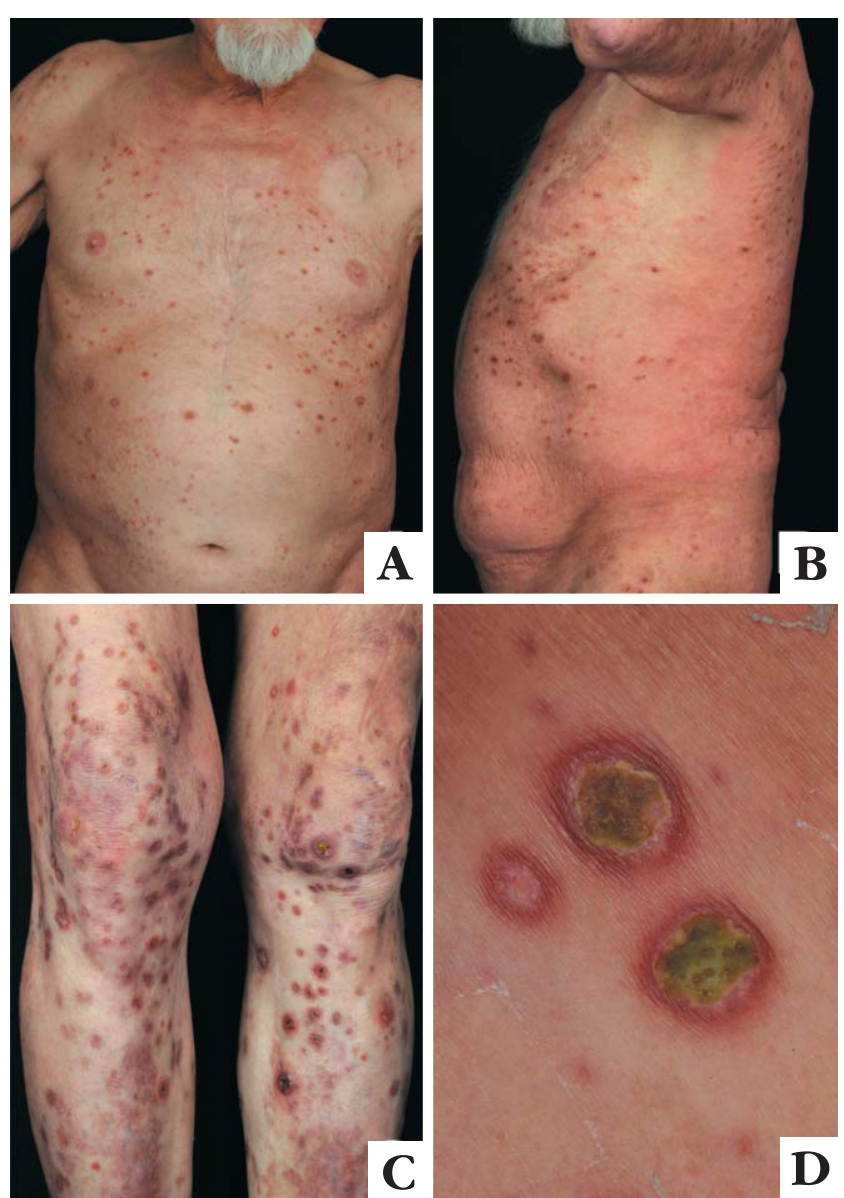

Figure 1: A, B, C, D. Multiple excoriated hyperkeratotic papules and nodules with central crust involving the whole integument potassium $5.5 \mathrm{mmol} / \mathrm{l}$ (3.5-5.0), HbA1c 8.0\% (4.3-5.9), parathormon $89.8 \mathrm{pg} / \mathrm{ml}$ (15.0-65.0), lymphocytes with $12 \%(20-40.0)$; uric acid $6.1 \mathrm{mg} / \mathrm{dl}$ (3.4-7.0) was within normal range.

Histopathology showed irregular epidermal hyperplasia with hypergranulosis, orthokeratosis and a cup-shaped depression of the epidermis with parakeratotic material, debris and extruded basophilic collagen fibres at the bottom (Figure 2). Fibrosis and a perivascular lymphoplasmacellular infiltrate were present in the dermis.

The diagnosis of ARPC was made. The patient was initially given a 2 -week course of antihistamines p.o.. Topically applied corticosteroids and 6-week narrow-band ultraviolet-B phototherapy were also tried. As pruritus and skin lesions persisted, allopurinol $100 \mathrm{mg}$ once/day p.o. was started. Skin lesions and pruritus improved within 4 weeks, in fact the lesions resolved to postinflammatory hyperpigmentations. Clinical response was maintained at 14-month followup visit with uninterrupted well-tolerated allopurinol therapy (Figure 3).

\section{DISCUSSION}

About one hundred ARPC cases have been reported in the English literature and ARPC has been observed mainly in patients with diabetes mellitus and/or chronic renal insufficiency, but it has been associated also with other endocrine disorders like hypothyroidism and hyperparathyroidism, liver dysfunction, sclerosing cholangitis, lung fibrosis, AIDS, pulmonary aspergillosis, scabies infection, leukemia, lymphoma and different malignancies. ${ }^{1}$ The pathogenesis is unknown. It has been hypothesized that mild superficial trauma (i.e. due to scratching) in patients with inherited susceptibility may lead to necrosis of

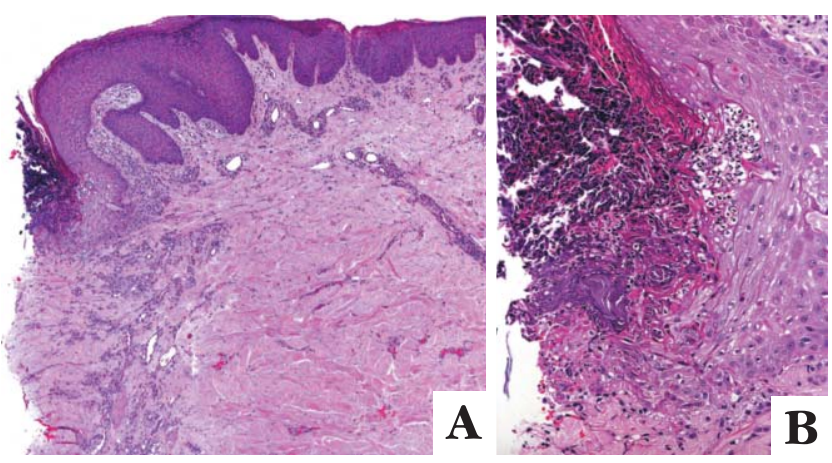

Figure 2: A. Acanthosis of the epidermis with hypergranulosis and ortho-parakeratosis. On the left side, cup-shaped depression of the epidermis with parakeratotic material and debris. In the dermis fibrosis, teleangiectatis vessels and aspecific lymphohistiocytic infiltrate. B. Cup-shaped depression of the epidermis which is filled by parakeratotic keratin and neutrophils. At the bottom basophilic collagen fibres in vertical orientation that are extruded 
papillary dermal collagen. ${ }^{1}$ Diabetic vasculopathy and hypoxic conditions as insufficient small blood vessels supply may be aggravating factors. ${ }^{1}$ Immunohisochemical and ultrastructural studies have shown that the extruded collagen is normal. ${ }^{7}$ Using immunofluorescence techniques, Herzinger et al. demonstrated the presence of collagens type IV and type VII within the keratin plug, and suggested that collagen IV may elicit an immune response that triggers its penetration through the epidermis. ${ }^{8}$

The typical umbilicated (secondarily crateriform) papules or nodules can be localized only on the trunk or extremities or can be diffuse involving the all integument. Lesions are usually very itchy and new lesions can appear as a Koebner's phenomenon due to continuous scratching. However, pruritus is a common symptom in most systemic diseases associated which ARPC, thus it is not clear whether ARPC is a primary condition or a reaction to scratching.

Histopathologic features depends on the evolution of the lesion. Early lesions shows epidermal acanthosis and accumulation of basophilic collagen in
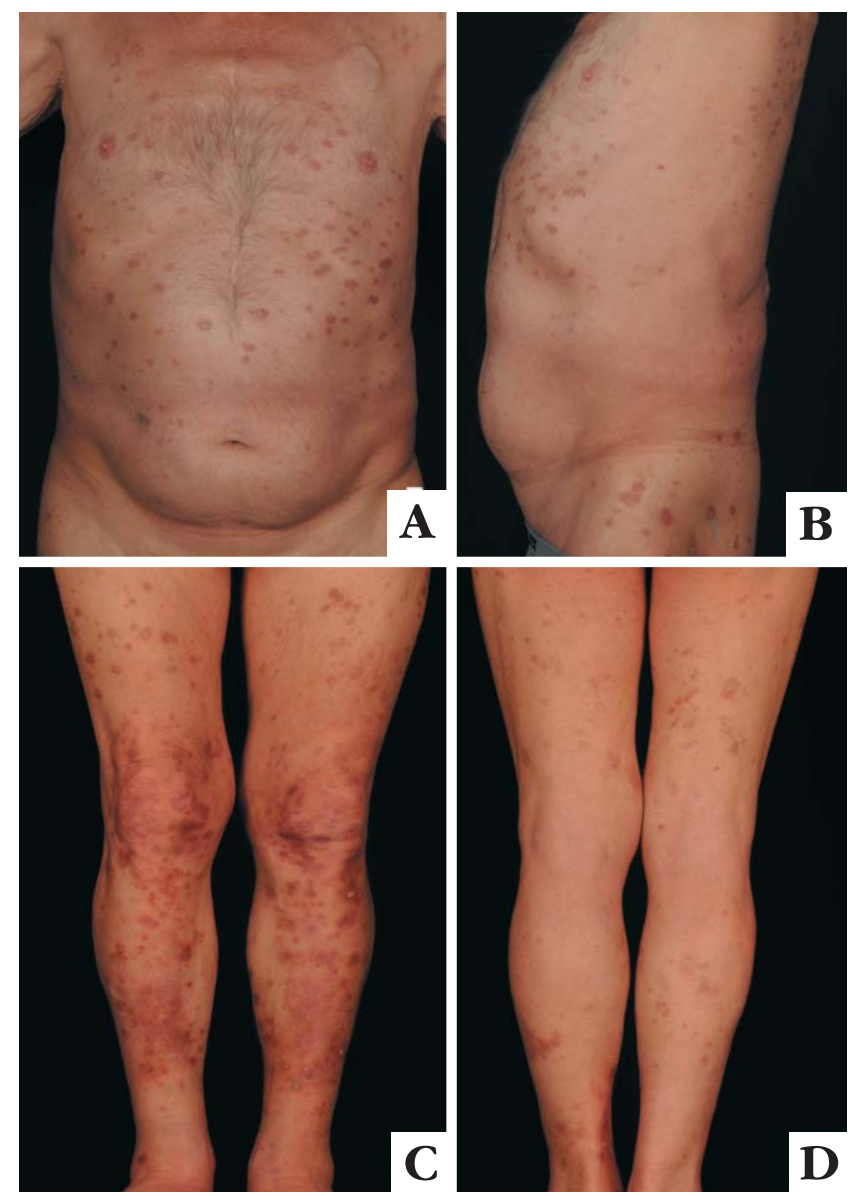

Figure 3: A, B, C, D. Multiple postinflammatory hyperpigmentations involving the whole integument after 8 months of treatment with allopurinol papillary dermis. Fully developed lesions show a dome-shaped epidermal depression (crater) filled with a parakeratotic plug, collagen and debris. Vertically oriented basophilic collagen fibres are extruded. Follicular involvement is present in $40 \%$ of cases. $^{1,7-10}$

Differential diagnosis includes mainly other perforating dermatoses like perforating folliculitis, elastosis perforans serpigininosa, Kyrle`s disease, perforating calcifying elastosis and perforating granuloma annulare. More than 100 cases of APRC have been reported, 18 (18\%) in the $70-79$ year group like our patient. $^{1}$

Treatment is difficult. ARPC usually improves when the coexisting systemic disease is treated. Numerous therapies have been tried in ARPC, including topical therapies like topical steroids, topical retinoic acid, phototherapy and systemic therapies like doxycycline, rifampicin and systemic retinoids. Still, no standard therapy is available. ${ }^{1}$

In some patients, allopurinol confirmed to be a valid and effective treatment. ${ }^{2-6}$ The exact mechanism of action is unknown; it has been speculated that allopurinol inhibits xanthine oxidase which decreases oxygen free radicals that cause collagen damage and might inhibit collagen cross-linking by advanced glycation endproducts due to an antioxidative effect. ${ }^{2 \cdot 4}$ To our knowledge, only twelve patients $(\mathrm{M}: \mathrm{F}=6: 6$; median age: 66,5 ; mean age: 67,6 ; range: $37-96$ ) have been reported as effectively treated with allopurinol. ${ }^{1 .}$ ${ }^{6}$ ARPC was associated with diabetes and renal insufficiency in 4 patients, with only diabetes in 4 and renal insufficiency in 2. Uric acid was within normal range in 8 patients. Allopurinol, 100mg/day p.o., was started in all patients; in one of them, however, the daily dose had to be increased up to $300 \mathrm{mg}$ and in another was reduced to $50 \mathrm{mg} /$ day. Improvement was noticed already within one and 4 weeks in 7 patients and within 24 months in 5 patients. ${ }^{1-6}$

Our experience supported by the literature suggests that allopurinol is a valid and effective treatment in patients with ARPC. Due to the rarity of ARPC, case series are difficult to collect but case reports should be encouraged including those in which allopurinol proved to be ineffective. $\square$ 


\section{REFERENCES}

1. Karpouzis A, Giatromanolaki A, Sivridis E, Kouskoukis C. Acquired reactive perforating collagenosis: current status. J Dermatol. 2010;37:585-92.

2. Hoque SR, Ameen M, Holden CA. Acquired reactive perforating collagenosis: four patients with a giant variant treated with allopurinol. Br J Dermatol. 2006;154: 759-62.

3. Gnanaraj P, Venugopal V, Sangitha C, Rajagopalan V, Pandurangan CN. A giant variant of acquired reactive perforating collagenosis associated with hydronephrosis: successful treatment with allopurinol. Int J Dermatol. 2009;48:204-6.

4. Querings K, Balda BR, Bachter D. Treatment of acquired reactive perforating collagenosis with allopurinol. Br J Dermatol. 2001;145:174-6.

5. Iyoda M, Hayashi F, Kuroki A, Shibata T, Kitazawa K, Sugisaki T, et al. Acquired reactive perforating collagenosis in a nondiabetic hemodialysis patient: successful treatment with allopurinol. Am J Kidney Dis. 2003;42: E11-3.

6. Krüger K, Tebbe B, Krengel S, Goerdt S, Orfanos CE. Acquired reactive perforating dermatosis. Successful treatment with allopurinol in 2 cases. Hautarzt. 1999;50:115-20.

7. Weedon D. Skin Pathology. 3rd ed. London (UK): Churchill Livingstone; 2010.

8. Herzinger T, Schirren CG, Sander CA, Jansen T, Kind P. A. Reactive perforating collagenosis - transepidermal elimination of type IV collagen. Clin Exp Dermatol 1996; 21: 279282.
9. Castro LGM, Nogueira MF, Valente NYS. Colagenose reativa perfurante adquirida associada a insuficiência cardíaca congestiva. An Bras Dermatol. 2001;76:437-9.

10. Badziak D, Lenhardt C, de Barros MF, Mandelli FL, Serafini SZ, Santamaria JR. Dermatose perfurante adquirida associada à insuficiência hepática em paciente transplantado de fígado. An Bras Dermatol. 2007;82:53-6.

MAILING ADDRESS:

Cesare Massone

Department of Dermatology, Medical University of Graz

Auenbruggerplatz 8, A-8036 Graz, Austria.

E-mail: cesare.massone@gmail.com

How to cite this article: Tilz H, Becker JC, Legat F, Schettini APM, Inzinger M, Massone C. Allopurinol in the treatment of acquired reactive perforating collagenosis. An Bras Dermatol. 2013;88(1):94-7. 